\title{
ASO Author Reflections: The MelFo-Study, UK: Effects of a Reduced Frequency, Stage-Adjusted Follow-Up Schedule for Cutaneous Melanoma IB-IIC Patients After 3 Years
}

\author{
Marc Moncrieff, MD, FRCS(Plast) ${ }^{1,2}$ (D) , Beverly Underwood, RGN ${ }^{1}$, Jennifer Garioch, MD, FRCP ${ }^{3}$, \\ Martin Heaton, MD, FRCS(Plast. $)^{4}$, Nakul Patel, FRCS(Plast. $)^{1}$, Esther Bastiaannet, PhD $^{5}$, \\ Josette Hoekstra-Weebers, $\mathbf{P h D}^{6,7}$, and Harald Hoekstra, $\mathrm{MD}, \mathbf{P h D}^{8}$
}

${ }^{1}$ Department of Plastic and Reconstructive Surgery, Norfolk and Norwich University Hospital, Norwich, UK; ${ }^{2}$ Norwich Medical School, University of East Anglia Faculty of Medicine and Health Sciences, Norwich, UK; ${ }^{3}$ Department of Dermatology, Norfolk and Norwich University Hospital, Norwich, UK; ${ }^{4}$ Department of Plastic Surgery, Norfolk and Norwich University Hospital NHS Foundation Trust, Norwich, UK; ${ }^{5}$ Department of Surgery, Leiden University Medical Center, Leiden, The Netherlands; ${ }^{6}$ Wenckebach Institute, Universitair Medisch Centrum Groningen, Groningen, The Netherlands; ${ }^{7}$ Integraal Kankercentrum Nederland Locatie Groningen, Groningen, The Netherlands; ${ }^{8}$ Department of Surgical Oncology, University Medical Center Groningen, Groningen, The Netherlands

\section{PAST}

The routine use of sentinel lymph node biopsy (SLNB) to accurately stage melanoma patients has been incorporated into most international melanoma guidelines. On average, over $80 \%$ of patients are sentinel node negative. ${ }^{1}$ However, these patients still require follow-up, since the risk of locoregional or distant spread, although comparatively low, remains a possibility. Approximately $90 \%$ of recurrences occur within 3 years of diagnosis for American Joint Committee on Cancer (AJCC) stage II melanomas, but for AJCC stage I melanomas; a significant proportion of recurrences occur after a substantial delay. ${ }^{2}$ Accordingly, it is challenging for national guidelines committees to devise simple follow-up schedules for melanoma patients.

\section{PRESENT}

The melanoma follow-up (MelFO) study is an international phase III randomized controlled trial where participants are randomized into two groups-one

(C) The Author(s) 2020

First Received: 25 April 2020;

Published Online: 10 July 2020

M. Moncrieff, MD, FRCS(Plast)

e-mail: marc.moncrieff@nnuh.nhs.uk following the conventional schedule recommended in the UK National Institutes for Health and Care Excellence (NICE) melanoma guidelines, ${ }^{3}$ and one whose follow-up was an AJCC stage-adjusted reduced schedule. Importantly, the primary endpoint for this study is patients' quality of life (QoL), although secondary endpoints include the usual standard outcomes data such as disease-specific and overall survival. We found that both cohorts expressed high satisfaction with their regimens $(>93 \%) .{ }^{4}$ Overall compliance with the follow-up schedules was high at the 1and 3-year timepoints (68.5\% and $66.5 \%$, respectively). At 3 years, no significant group effect was found on any patient-reported outcomes measure scores, indicating no QoL difference between the follow-up protocols. The recurrence rate was identical (approximately 16\%) and self-examination was the main method of detection for both groups (approximately 70\%). Melanoma-specific survival was also identical.

\section{FUTURE}

These reflections were written at a time when most modern healthcare services have been disrupted beyond recognition during the COVID-19 pandemic. It is likely that many services will be rationalized in the future, once the pandemic subsides. Accordingly, evidenced-based follow-up regimens will be needed to ensure that the 
appropriate balance is struck between diagnosing early the few recurrences in low-risk groups such as these and not overburdening both patients and society alike.

The UK MelFO study has shown that 3 years after staging with a negative SLNB, AJCC stage IB-IIC cutaneous melanoma patients assigned to the prescribed reduced stage-adjusted follow-up schedule reported no difference in levels of anxiety, cancer worry, and mental health-related QoL when compared with those of patients assigned to the follow-up schedule as currently advised in the UK NICE melanoma guideline. These results mirror the findings of the Dutch group who recently reported very similar results using the same protocol in $2019 .^{5} \mathrm{We}$ anticipate reporting the combined data for the final outcome of the study at the end of 2020, with adequate power to detect any difference in recurrence rates. It is our hope that the results will assist future national guideline committees designing protocols for the follow-up of cutaneous melanoma patients.

DISCLOSURE The authors declare that they have no conflict of interest.

OPEN ACCESS This article is licensed under a Creative Commons Attribution 4.0 International License, which permits use, sharing, adaptation, distribution and reproduction in any medium or format, as long as you give appropriate credit to the original author(s) and the source, provide a link to the Creative Commons licence, and indicate if changes were made. The images or other third party material in this article are included in the article's Creative Commons licence, unless indicated otherwise in a credit line to the material. If material is not included in the article's Creative Commons licence and your intended use is not permitted by statutory regulation or exceeds the permitted use, you will need to obtain permission directly from the copyright holder. To view a copy of this licence, visit http://creativecommons. org/licenses/by/4.0/.

\section{REFERENCES}

1. Morton DL, Thompson JF, Cochran AJ, et al. Final trial report of sentinel-node biopsy versus nodal observation in melanoma. $N$ Engl J Med. 2014;370(7):599-609.

2. Francken AB, Shaw HM, Accortt NA, Soong S-J, Hoekstra HJ, Thompson JF. Detection of first relapse in cutaneous melanoma patients: implications for the formulation of evidence-based follow-up guidelines. Ann Surg Oncol. 2007;14(6):1924-33.

3. Melanoma: assessment and management. Guidance and guidelines. NICE. https://www.nice.org.uk/guidance/ng14. Accessed 22 Nov 2018.

4. Moncrieff MD, Underwood B, Garioch JJ, et al. The MelFo-study UK: effects of a reduced frequency, stage-adjusted follow-up schedule for cutaneous melanoma IB-IIC patients after 3-years. Ann Surg Oncol. 2020. https://doi.org/10.1245/s10434-020-087582.

5. Deckers EA, Hoekstra-Weebers JEHM, Damude S, et al. The MELFO study: a multicenter, prospective, randomized clinical trial on the effects of a reduced stage-adjusted follow-up schedule on cutaneous melanoma IB-IIC patients-results after 3 years. Ann Surg Oncol. 2020;27(5):1407-17. https://doi.org/10.1245/s10434019-07825-7.

Publisher's Note Springer Nature remains neutral with regard to jurisdictional claims in published maps and institutional affiliations. 